\title{
La lógica del exceso en los restaurantes de comida rápida'
} The logic of excess in fast-food restaurants

\author{
Baltasar Fernández Ramírez; Elia Esquirol Arias; Cristina Rubio Jiménez; Enrique \\ Baleriola Escudero \\ Universidad de Almería \\ bfernan@ual.es; earias.e@gmail.com; xtyna@hotmail.com; ebebaes@gmail.com
}

\section{Historia editorial Resumen}

Recibido: 08/07/2011
Primera revisión: 26/02/2012
Aceptado: 04/11/2012

\section{Palabras clave}

Obesidad

Comida rápida

Ambientes obesogénicos

Ciudades obesas
La obesidad está siendo considerada como uno de los mayores problemas para la salud pública de nuestro tiempo. El modelo norteamericano de alimentación urbana, ejemplificado en las cadenas de comida rápida, se ha extendido por todo el mundo, trasladando fuera de sus fronteras la preocupación por la gordura y su consideración como una patología de graves consecuencias. Analizamos en este trabajo los valores y el simbolismo de la iconografía de McDonald's, bajo la tesis de que la lógica del exceso, la simbología encarnada a través de los espacios y la cuestión de la obesidad se vinculan formando un discurso sutil que refuerza el estigma de las personas obesas. La metáfora del exceso forma parte central de los mensajes, ambientación y diseños de la cadena, desde sus reclamos publicitarios hasta la presentación de la comida y la dinámica del comportamiento del cliente. Nuestra conclusión es que McDonald's es un fiel reflejo de las características sociales vinculadas al concepto de posmodernidad (simulacro, superficialidad, carácter efímero o líquido de los acontecimientos sociales). No nos interesa si la comida rápida contribuye al incremento de la obesidad. Hablar sobre McDonald's es asociar la obesidad con una imagen de alimentación fuertemente cuestionada, y por lo tanto, establecer el discurso sobre la corpulencia y la gordura en el terreno del estigma y el rechazo social.

\section{Abstract}

\section{Keywords}

Obesity

Fast food

Obesogenic environments Fat city
Obesity is considered as one of the main problems for public health. The USA urban model of feeding, illustrated through the system of fast food restaurants, is extended all over the world, translating the worry and the consideration of obesity as a pathology with severe consequences. We analyze here the values and symbolism of McDonald's. Our thesis poses that the logic of excess, the symbology tied in and through the environments, and the question of obesity are linked together, creating a subtle discourse that reinforces the obesity stigma. The metaphore of excess takes a central part in the messages, ambient and designs, from the interiors advertising to the presentation of meal and the clients programs of behaviour. We conclude that McDonald's fits well with the social characteristics associated to the concept of postmodernity (simulacra, superficiality, ephemeral or liquid social interaction). We don't think about the contribution of fast food to obesity. To talk about McDonald's is the same than to associate obesity with a very criticized image of feeding, and therefore, to establish the discourse about fatness and corpulence in the domain of social stigma and rejection.

No todo funciona con exceso, pero nada, de un modo u otro, está ya a salvo de las lógicas de lo extremo.

Gilles Lipovetsky (2006, p. 59)

Fernández Ramírez, Baltasar; Esquirol Arias, Elia; Rubio Jiménez, Cristina y Baleriola Escudero, Enrique (2012). La lógica del exceso en los restaurantes de comida rápida. Athenea Digital, 12(3), 187-200. Disponible en http://psicologiasocial.uab.es/athenea/index.php/atheneaDigital/article/view/FernandezR

\footnotetext{
${ }^{1}$ Este artículo es una versión ampliada y corregida del texto presentado en el XI Congreso de Psicología Ambiental (Almería, febrero, 2011).
} 


\section{Obesidad, ciudades y comida rápida}

El número de establecimientos de comida rápida, junto a otros indicadores relativos a la presencia de espacios verdes, han sido utilizados para dotar de contenido a los conceptos de ciudades obesas y de ambientes obesogénicos, es decir, aquellos que favorecerían el sobrepeso debido a la presencia de locales que promueven modos de alimentación hipercalóricos y a la ausencia de espacios y diseños ambientales que promuevan el ejercicio físico (Swinburn, Egger y Raza, 1999). John W. Sommer (1975) utilizó la expresión de ciudades obesas como metáfora para aludir al fenómeno del sprawling, con el que se describe el modelo norteamericano de crecimiento horizontal de las ciudades, en el que las grandes distancias se relacionan con un mayor uso del automóvil y una menor disponibilidad de tiempo para la alimentación (Sui, 2003).

Está implícito un concepto de gordura como resultado de un supuesto equilibrio energético entre la ingesta y el consumo de calorías (la energy balance equation, que quizá deberíamos entender simplemente como la metáfora del equilibrio energético, pues no es otro su valor semántico). En concordancia, los psicólogos ambientales redefinen el ambiente y los objetos que nos rodean en virtud de las oportunidades o limitaciones que disponen para la realización de un mayor ejercicio físico en nuestras actividades diarias, o de manera más o menos sutil, para realizar una cantidad de ingesta comparativamente mayor (Kirk, Penney y McHugh, 2010; Wells, Ashdown, Davies, Cowett y Yang, 2007). El diseño liviano de la ropa, la realización de tareas domotizadas, la accesibilidad a modos de transporte automóviles, etc., que pueden ser entendidos como mejoras de nuestra calidad de vida en otros contextos de discurso, son redefinidos aquí como obstáculos que determinan una vida sedentaria. Del mismo modo, la presencia de cierto tipo de restaurantes o supermercados que acercan la comida rápida y la precocinada, contribuirían a crear estilos de vida y de alimentación en los que abunda la ingesta de alimentos hipercalóricos.

Jeffery Sobal y Brian Wanskink (2007), por ejemplo, realizan un imaginativo análisis de los escenarios alimenticios ("paisajes", los llaman ellos, subrayando su componente visual), en sus distintos niveles de mediación entre la persona y la comida a su disposición: el orden en que se presentan los alimentos, la proximidad, el tamaño de los recipientes y de las porciones de comida, entre otros muchos elementos particulares, dificultarían la percepción consciente de las cantidades y la consiguiente decisión de finalizar la ingesta). Subyace aquí la idea de que la ingesta es una actividad rutinaria algo automatizada (irreflexiva), en la que cobran importancia todo tipo de marcadores o environmental cues que vendrían a determinar el inicio, la cantidad y la finalización de la ingesta.

Estas líneas de reflexión mantienen una lógica causal determinista que quisiéramos descartar explícitamente. Las metáforas de la ciudad obesa y de la balanza energética han venido a ser utilizadas como descripciones válidas de una supuesta realidad social en la que factores físicos, ambientales y ecológicos son las causas potenciales del comportamiento, prescindiendo por completo de la ineludible dimensión simbólica del mismo. El determinismo redefine el ambiente como uno de los polos simples en la ecuación causal "ambiente produce comportamiento"2. El ambiente sólo sería relevante por su supuesta influencia, y no como depósito de significados que anclan u objetivan el discurso sobre la obesidad, ignorando que tanto el ambiente como las personas son interpretadas (reificadas) al unísono dentro del discurso, creando la ilusión de que existiría una influencia causal en algún sentido, y no que las características de ambos son efectivamente coherentes porque las prácticas discursivas que comparten también lo son.

\footnotetext{
${ }^{2}$ Aunque la psicología ambiental defiende en teoría una concepción sociofísica del espacio, en la práctica cae con frecuencia en esta reducción ambientalista, forzada sobre todo por la lógica causal simple de sus métodos de investigación (Aragonés y Amérigo, 2010).
} 
Desde una posición crítica (feminista y postestructuralista en este caso), Michael Gard (2009) reclama que exploremos nuevos planteamientos de estudio, no para descubrir los determinantes de la obesidad entendida como "variable" individual, sino para caracterizar nuestra sociedad como portadora de un estado de la cuestión en que la obesidad resulta relevante, extendida y problematizada ${ }^{3}$. Tanto el cuerpo como el espacio quedan aquí reconceptualizados como sendas parcelas del orden cultural normativo, y las cuestiones relativas a la alimentación ceden su foco individual para plantearse como des/órdenes o como un esfuerzo de reapropiación a través de la construcción del propio cuerpo enfrentado a los dictados del rol de género, un acto interpretado como rebelde desde el orden social establecido (Eckermann, 2009; Malson y Burns, 2009). Hablar de comida se interpreta como un proceso comunicativo cargado de significados en un contexto discursivo específico.

Por nuestra parte, entendemos que la conjunción de diversos discursos y opiniones generadas en ámbitos sanitarios, políticos y estéticos, han venido creando las condiciones para que la población, incluso las personas obesas, acepten como obvio un planteamiento crítico y estigmatizador estricto que debe ser cuestionado. Estos discursos están así señalando a un importante sector de la población, el cual queda revestido de connotaciones que desafían a ciertos valores sociales (relacionados con el culto al cuerpo o el control de uno mismo), y creando serias dificultades psicológicas y sociales a multitud de mujeres $^{4}$ en nuestras sociedades occidentales, ocupadas en realizar un esfuerzo baldío y de fines dudosamente deseables (Fernández-Ramírez, Esquirol y Rubio, 2009). Promover el adelgazamiento nos resulta un modo sutil de estigmatización contra el que tenemos algunas precauciones. Ser delgada no es una necesidad sanitaria, sino una imposición ética y estética ${ }^{5}$. De igual modo, no pensamos que la ciudad sea un sitio que produzca obesos o fuerce a las personas a engordar mediante oscuros o sutiles mecanismos de influencia. Que haya restaurantes de comida rápida no engorda: basta con ir a otros lugares o ingerir alimentos menos calóricos, además de que la relación entre ejercicio, alimentación y peso es peculiar en muchas personas ${ }^{6}$. En su lugar, nos resulta más interesante entender estos lugares como espacios donde el exceso, la cantidad, la rapidez, e incluso la gordura se han normalizado y forman parte de los lenguajes que nos rodean y que surgen de las subculturas de la moda, el ocio o la alimentación. La articulación entre lo simbólico, lo espacial y lo corporal se sostiene en el modo en que las prácticas discursivas son corporizadas o encarnadas a través de este tipo de elementos (símbolos,

\footnotetext{
${ }^{3}$ Nuestro marco teórico está influido por la crítica feminista, preocupados por la estigmatización que el discurso antiobesidad genera en la mujer. Conceptos como la medicalización del cuerpo y la gubernamentalización de la vida cotidiana (Foucault, 1977; Rose y Miller, 1992) ayudan a replantear la cuestión de la obesidad en términos de un orden social basado en los valores del culto al cuerpo y la estética de la delgadez, que se encuentra por lo tanto amenazado (Eckermann, 2009; Gard, 2009). La crítica feminista ha sido especialmente incisiva al profundizar en las posiciones postestructuralistas, mostrando cómo la discriminación relacionada con el género se impone de maneras sutiles a través de una extensa red de implicaciones y supuestos normativos y valorativos que presiden la definición corporal de la mujer. Con independencia de que tratemos con problemáticas más o menos marcadas por la cuestión del género, la teorización feminista crítica nos ofrece modelos de razonamiento sugerentes y válidos para nuestro propio marco teórico en el contexto de este trabajo.

${ }^{4}$ Mujeres y hombres, aunque sobre todo las primeras. El discurso antiobesidad no distingue entre categorías de género (ni en sus argumentos médicos ni en los estéticos), aunque debe reconocerse que la presión social para el mantenimiento de ciertos estándares difusos de imagen corporal incide y perjudica sobre todo a las mujeres, que sufren una demanda especial para definir su identidad pública a través de su presentación corporal (la mujer como escaparate; Hartley, 2001).

${ }^{5}$ Las recomendaciones médicas tienden a simplificarse y a no hacer distinción entre un sobrepeso moderado y una obesidad mórbida, e incluso más allá, generalizando el valor de la delgadez sin que sea evidente su equivalencia en términos de salud y enfermedad. En este sentido, podemos afirmar que la delgadez no es una necesidad, sino un valor ético y estético sobregeneralizado.

${ }^{6} \mathrm{Y}$ esto sin tener en cuenta las variadas razones que pueden dar cuenta del peso de una persona, entre las cuales no sólo se cuenta el ejercicio físico y la alimentación. La metáfora energética ha resultado reduccionista en este sentido, y la mayoría de las personas, especialistas incluidos, hablan del peso de manera muy estereotipada, más por coherencia con las metáforas extendidas que por conocimiento o reflexión.
} 
objetos, cuerpos). De ningún modo deseamos proponer modelos causales simplistas, sino una construcción discursiva conjunta que se nutre de (y a partir de) lo espacial y lo corporal. El espacio se constituye así en depósito del significado, como encarnación de los discursos, como extensión de la simbología de los cuerpos, que se impregnan de sentido en relación con el contexto espacial.

Los actuales discursos oficiales sobre la salud y la belleza, difusos e intangibles por su naturaleza semántica y su continua reconstrucción, cristalizan o se virtualizan en estilos de vida, en pautas de alimentación de distintas características, en espacios pensados para ser coherentes con el modelo de alimentación aceptado, o en nuestros propios cuerpos, modificados y trabajados para parecer delgados o para esconder formas y pesos no aceptables (Braziel y LeBesco, 2001). La normalización de estilos, ambientes y cuerpos, refuerza la validez de la crítica y estigmatiza o señala por mero contraste a todo lo que no encaje con el modelo (la mera enunciación de lo normal crea el campo semántico y normativo de lo anormal). En este contexto social, los restaurantes de comida rápida se presentan como espacios no saludables, espacios estructurados y organizados siguiendo un discurso de la alimentación y el ocio presidido por valores como la rapidez, la cantidad o lo barato, enfrentados con los parámetros aceptados de la vida sana ${ }^{7}$. No son "malos" porque promuevan la obesidad, sino porque desafían el estilo de vida políticamente correcto de nuestro contexto cultural.

Partiendo de una lógica del exceso (Lipovetsky, 2006), hemos analizado en este estudio algunas claves ambientales en el funcionamiento de los establecimientos de comida rápida, fundamentalmente la hamburguesería norteamericana McDonald's, cuyo modelo de restaurante ha sido adaptado en líneas generales por diversas cadenas o franquicias de restauración. Nuestra tesis general postula inicialmente la rapidez y el exceso (tamaño, cantidad, carga) como elementos semánticos centrales en el lenguaje que estos establecimientos hablan, desplegando un simbolismo característico que se aprecia en muchos de sus elementos y procesos, desde la imagen de marca hasta el producto, pasando por la ambientación de los locales. McDonald's y la obesidad forman parte del mismo antidiscurso de la salud idealizada, son la objetivación de lo indeseable, con la consecuencia discursiva de que ambos se utilizan para desprestigiase mutuamente en un bucle falaz que esconde una retórica estigmatizadora que debe ser puesta de manifiesto y cuestionada.

Nuestra fuente de información directa parte de un análisis de corte etnográfico, con observaciones participantes realizadas en varios locales de la cadena McDonald's de nuestra ciudad durante los meses de septiembre a diciembre de 2010. Se complementa con un análisis icónico (Gómez, 2001) de una muestra de imágenes extraídas de distintas páginas web durante las mismas fechas. Ambos materiales son interpretados atendiendo tanto a una dimensión ecológica (distancias, formas) como narrativa (mensajes, símbolos), con objeto de extraer algunos componentes discursivos relevantes de los elementos de la ambientación y del programa de comportamientos propio de los restaurantes (ecología narrativa).

Inicialmente, describiremos algunas características relevantes de los locales, incluyendo los valores señalados por George Ritzer (1966) bajo la conocida etiqueta de macdonalización; posteriormente, realizaremos un imaginario recorrido por los restaurantes, desde el exterior hasta el interior, y de ahí hasta el momento del almuerzo y la salida del restaurante, enfatizando los valores y elementos simbólicos que creemos adivinar en los paisajes ambientales de los locales. Concluiremos poniendo en

\footnotetext{
${ }^{7}$ En el imaginario popular (que impregna a su vez de maneras sutiles las propuestas de la ciencia o de la tecnocracia médica), el discurso de la salud comprender valores y lugares comunes como la tranquilidad sin prisas, la sobremesa con amigos, la calidad, la brevedad (lo bueno, si breve...; la moderación, el justo sentido del término medio), el precio justo (lo barato es caro...), etc.
} 
relación el estilo McDonald's de restauración con los caracteres comunes de nuestras ciudades postmodernas.

\section{El éxito del modelo McDonald's}

McDonald's dispone de más de 26000 restaurantes distribuidos por 126 países, y abre de tres a ocho locales nuevos por día en todo el mundo, vendiendo alrededor de 145 hamburguesas por segundo ${ }^{8}$. La ambientación de los locales, el mobiliario, la disposición espacial, los utensilios de cocina, así como los proceso de elaboración y entrega de los menús, están previstos y optimizados al detalle, sirviendo cada pedido en un tiempo máximo de cinco minutos, hasta alcanzar, en un restaurante medio de nuestra localidad, entre las 7300 unidades en un día entre semana, y las 10200 en un solo día del fin de semana.

Sobre la calidad de sus productos, poco tenemos que decir. Baste apuntar que, frente a la apariencia de rapidez del servicio, los alimentos son sometidos a procesos de alta elaboración en comparación con los restaurantes tradicionales. Un típico menú de comida rápida podría contener más de setenta sustancias, de las que más de cuarenta son aditivos, colorantes, aromas, y otras sustancias añadidas de forma artificial. A pesar de su planteamiento sensacionalista y algo simplificador, el documental SuperSize me (Spurlock, 2004) ofrece un testimonio personal sobre el ritmo de engorde y los trastornos de salud ocasionados por una dieta basada exclusivamente en la comida de este tipo de restaurantes.

Dentro de su sector de mercado, McDonald's lleva diez años siendo la empresa más rentable de Estados Unidos. En todo el mundo, sus locales ofrecen un menú idéntico, con leves variaciones relacionadas con los productos, modo de elaboración o gustos propios de cada zona cultural (cerveza en Alemania, vino en Francia, fideos en Oriente). En los países árabes y en Israel, los menús se preparan atendiendo a las prescripciones religiosas que marcan las leyes de cada Estado.

Su presencia es cada vez mayor, debido en parte a su peculiar estilo de comida y a su bajo coste: alimentos baratos, con alto valor energético, presentados en tamaños gigantes - supersize-, servidos y consumidos en un tiempo reducido. McDonald's ha sido patrocinador de los Juegos Olímpicos y de la Eurocopa, y el payaso Ronald McDonald's, icono de la cadena, es más conocido por los niños norteamericanos que cualquier otro personaje histórico. Entre sus estrategias publicitarias, elaboran mensajes para un público de especial protección, como es el infantil, en los que destacan las promociones y regalos asociados a la compra o consumo de un producto, por encima de su valor nutritivo o alimenticio. Las cadenas punteras en el sector desarrollan campañas con gran presión en los medios de comunicación, que les llevan a ocupar los primeros puestos en los rankings de inversión publicitaria en España.

\section{Los valores del éxito}

George Ritzer (1996) ha analizado el fenómeno McDonald's como un modelo de la actual globalización, en la que un archipiélago de locales casi idénticos sirven los mismos productos en los cinco continentes, creando una proximidad de costumbres en torno a patrones culturales originalmente estadounidenses. La macdonalización remite a la homogeneización cultural y a la reducción de la distancia psicológica, a pesar de las distancias geográficas. La extensión del propio tipo morfológico de obesidad norteamericano está implícito en esta discusión, al igual que la disputa, originaria del mismo país, sobre

\footnotetext{
${ }^{8}$ Información ofrecida en la página oficial de la cadena.
} 
el orgullo gordo, la supuesta pandemia y la estigmatización de las personas obesas (Braziel y LeBesco, $2001)^{9}$.

Ritzer analiza el atractivo de McDonald's en función de una serie de características que lo distinguen y le dan un sello especial como empresa de restauración. Nosotros las hemos reinterpretado señalando cuatro valores clave: rapidez, sencillez, confianza y seguridad.

Rapidez. Teniendo en cuenta el ritmo acelerado de nuestro estilo de vida urbano, o el actual modelo parental, en el que ambos padres trabajan fuera de casa, la rapidez para solucionar un almuerzo o una cena añaden atractivo al servicio prestado. La industria de la comida rápida se ha beneficiado de los cambios demográficos, ya que provee a bajo coste las comidas que ya no se preparan en casa y contrata, con sueldos también bajos, a millones de mujeres jóvenes que necesitan ingresos extras (Macdonald y Sirianni, 1996).

El actual modelo urbano tiende a una concepción multicéntrica y a la concentración diferencial de los espacios residenciales, laborales, de ocio, etc. (Dear, 2000). La respuesta de los ciudadanos es un estilo de vida dinámico, de movimiento continuo, generalmente en automóvil, en el que la eficacia es un valor añadido de la comida rápida, incluida la posibilidad de obtenerla sin bajar del coche. El modelo de la comida rápida ofrece —o al menos, así lo parece — un método eficiente para satisfacer buena parte de nuestras necesidades alimenticias.

Sencillez. En segundo lugar, McDonald's brinda una alimentación y un servicio fácilmente cuantificados y valorados. Las variantes supersize (el Cuarto de libra, el Big Mac o la bolsa de patatas fritas grande) son ofrecidas y aceptadas con normalidad, mientras que los McMenús a precios reducidos (hamburguesa o helado por un euro) forman parte de las estrategias innovadoras de lucha contra la competencia. Cantidad ha llegado a ser sinónimo de calidad. Nuestra cultura tiende a creer profundamente que, en general, lo más grande es lo mejor ${ }^{10}$.

La valoración del servicio es rápida y directa. El cliente siente que recibe una enorme cantidad de comida, y que, como contrapartida, apenas se desprende de una pequeña suma de dinero. Tales cálculos ignoran que el éxito de los establecimientos de comida rápida y la extensión del modelo a otros negocios, indican que estas deducciones son erróneas y que estos negocios son en realidad muy rentables para sus propietarios.

Confianza. En tercer lugar, McDonald's ofrece un servicio previsible. El Big Mac que se puede adquirir en Barcelona será idéntico al que se sirve en Almería o en Tokio. También el que se pida la semana o el año que viene será idéntico al que se haya comido hoy. Reconforta saber que McDonald's no brinda sorpresas, es decir, que la comida tomada en un determinado momento o lugar es idéntica a la que se comerá en otro sitio o a otra hora. El siguiente Big Mac no será delicioso, pero tampoco excepcionalmente horroroso: sencillamente, será el mismo. La imagen de marca y la estética de

\footnotetext{
${ }^{9}$ Inevitablemente, al entrar en contacto con nuestro peculiar sociohistoria española y europea, estas discusiones foráneas se funden y se confunden con otras líneas de reflexión pública europeas en relación con la moda, la salud y la belleza física. Nada tiene que ver la imagen del comedor de hamburguesas estadounidense con la corpulencia típica de la matriarca mediterránea, la gordura relacionada con el consumo de productos del cerdo, la obesidad derivada de los trastornos del metabolismo o los cuerpos rollizos de los infantes y los niños. Sin embargo, todas ellas se han fundido bajo el estereotipo del obeso, en una burda simplificación que debe ser cuestionada con rotundidad.

10 George Lakoff y Mark Johnson (1998) discuten profusamente cuán arraigadas se encuentran este tipo de metáforas en nuestro acervo cultural. No asombra que este tipo de esquemas o heurísticos de pensamiento sean asumidos con semejante facilidad, dado que ya forman parte histórica en muy diversas manifestaciones de nuestra cultura. No se trata de una cuestión de mera funcionalidad, sino de que forman parte de la base histórica de las estructuras simbólicas de nuestro pensamiento.
} 
exteriores, interiores y productos, anuncian una homogeneidad tranquilizadora. El éxito del modelo McDonald's sugiere que mucha gente desea un mundo sin sorpresas.

Seguridad. Todos los McDonald's son copias de un modelo altamente estandarizado y mecanizado, en el cual, la mano de obra humana es sustituida por tecnología. Los empleados han sido formados para realizar un número limitado de acciones, la variedad de menús es muy reducida y tanto el espacio como el proceso de preparación están analizados y diseñados hasta el mínimo detalle. La disposición de los ingredientes, las cantidades utilizadas en cada menú o los movimientos de los trabajadores en el espacio del local, están estudiados con precisión para asegurar que el resultado sea rápido e idéntico en cualquier restaurante de la cadena. Incluso el comportamiento de los clientes está orientado y previsto, aunque de una manera más sutil e indirecta. Líneas marcadas en el suelo, menús limitados, opciones escasas y asientos incómodos persiguen que los usuarios se limiten a lo previsto: comer rápidamente y marcharse. Además, la opción de hacer el pedido desde el propio coche (o también a pie) a través de una ventanilla, acelera el proceso de consumición y reduce el tiempo de estancia en el local.

La optimización de procesos exige sustituir la mano de obra por tecnología, como en el caso de la máquina de refrescos que se cierra automáticamente cuando el vaso está lleno, la freidora de patatas que emite un pitido cuando están listas, la caja registradora programada para eliminar la necesidad de que un cajero tenga que calcular precios y cantidades, y puede que, en tiempos futuros, el robot capaz de hacer hamburguesas (existen ya prototipos experimentales). El resultado es que McDonald's es capaz de ofrecer a los clientes una gran seguridad respecto de la atención y el servicio que recibirán.

\section{Un recorrido por el exceso}

La imagen exterior. Diferentes estrategias han hecho que los establecimientos McDonald's ganen visibilidad, incluso antes de llegar al establecimiento. Siguiendo un modelo norteamericano de rótulos de grandes dimensiones, los reclamos presentes en el exterior de los locales de carretera son de un tamaño especialmente grande y muy llamativos. No es extraña la presencia de sus restaurantes en áreas de servicio de las autopistas o en las zonas urbanas próximas a las vías de incorporación, ofreciendo la posibilidad de comer y continuar el viaje con rapidez. Si el cliente lo desea, un recorrido interior sencillo y legible rodea el edificio para que el coche acceda fácilmente hasta la ventanilla exterior y obtenga rápidamente la comida para el camino. Están presentes en estaciones de ferrocarril, tren y aeropuertos, y en la mayoría de los cientos de centros comerciales de nuestra geografía urbana, en las estaciones intermodales y en los centros tematizados de nuestras ciudades, los nuevos espacios de la vida pública urbana. La sobrecarga de elementos y el colorido chillón, en el que predominan el rojo y el amarillo puros, la intensidad de la iluminación de la cartelería, son características que aseguran la visibilidad a cierta distancia. La presencia ubicua de la estética y la cultura McDonald's contribuye a crear la imagen de rapidez y superficialidad de nuestra época, que Pep Vivas, Isabel Pellicer-Cardona y Óscar LópezCatalán (2008) tratan mediante el concepto de sociabilidad transitoria, espacios que ofrecen un potencial mínimo de apropiación y sin embargo están sobrecargados de elementos identificatorios.

El exterior del local está diseñado con lujo de detalles, hasta dominar el campo perceptivo de los potenciales usuarios que se encuentran cerca, creando la atrayente impresión de estar ya dentro del local. Aunque el diseño esté integrado con el contexto urbano donde se ubican los restaurantes, estos elementos exteriores distintivos contrastan vivamente con las texturas, las dimensiones o el estilo de los edificios circundantes, de tal modo que hacen más llamativo el reclamo. La estética McDonald's se ha impuesto entre nosotros y es desde hace tiempo una presencia normal, a pesar de la insuficiente coherencia con el estilo de las edificaciones y de la publicidad al uso en nuestras ciudades. Ya se 
presenten en un contexto arquitectónico reciente, en barrios tradicionales o en centros comerciales, ni su estética colorida y ni la $M$ que simboliza a la cadena pasarán desapercibidas.

En muchos centros comerciales, no existe una delimitación precisa entre el interior del restaurante y el espacio de tránsito adyacente, de tal forma que el mero deambular te introduce inevitablemente en el local, gracias a la visibilidad de productos, superficies y carteles, a la proximidad del mostrador de pedido o a la presencia de mesas en los espacios exteriores. Algo similar sucede en los restaurantes alojados en edificios independientes, los cuales disponen de accesos y áreas de aparcamiento propias. El transeúnte y el visitante transforman su rol en cliente con gran facilidad y apenas sin reparar en ello. No es que el diseño esté integrado en el centro comercial o en los espacios circundantes, es que éstos pierden sus cualidades diferenciales para convertirse en espacios funcionalmente integrados en el restaurante (Vivas, López-Catalán, Fernández-Ramírez y Pellicer-Cardona, en prensa). El restaurante parece mayor de lo que es, con independencia de su extensión propiamente dicha.

La entrada al local. Ya desde el exterior, se presenta como un espacio muy cuidado, pulcro y distintivo, plagado de iconos y elementos autorreferenciales. No se trata de la mera llegada al restaurante, sino que el cliente está entrando al mundo McDonald's, un mundo aparte en el que vivir las experiencias originales de la cadena. Ningún negocio tradicional se parece, ninguno se confunde con él y ninguno te dará la misma comida o la misma experiencia. Cierto aire futurista o perfectamente contrario a la imagen tradicional de la restauración, sugiere un espacio irreal, impostado o simulado, un edificio con rasgos de gusto infantil, de película de animación, donde los niños entran a jugar, y donde sirven una comida económica y rápida. Un sueño hecho realidad, una mentira convertida en verdad evidente para todos.

En muchos locales, esta sensación continúa en el interior, con diseños originales que combinan los colores vivos con cierta sensación de informalidad adaptada a los gustos infantiles. En otros locales, prima completamente la funcionalidad y la entrada podría confundirse con los pasillos y salas de espera de un centro médico. La familiaridad y proximidad que ofrecen los primeros contrasta con la funcionalidad que sugieren los segundos, nada con lo que distraerse, mera eficiencia en el paso rápido y descuidado por el restaurante: hacer el pedido y retirarlo para ser comido deprisa o ser consumido fuera del local.

Dentro, el recorrido es sencillo y rápido. La imagen exterior encuentra un reflejo coherente en el interior. Una sucesión de carteles a gran escala muestran hamburguesas perfectas y atrayentes, con doradas patatas para acompañar y bebidas refrescantes que parecen estar al alcance de la mano. Las fotografías son grandes, luminosas y brillantes, de gran calidad en el retoque. La zona infantil de juegos, presente en muchos locales, a veces con grandes dimensiones, delata la preocupación por el perfil familiar de sus clientes, ningún otro restaurante ofrece esta posibilidad. Ir a comer es un juego, una fiesta en la que el tiempo dedicado a la comida propiamente dicha es un paréntesis en el rato de juego: divertido, colorido y seguro. Los padres pueden disfrutar de unos momentos de tranquilidad y relajarse de la constante obligación de atender a los niños.

El mostrador. Avanzamos. Unos pocos pasos separan del mostrador, situado normalmente al fondo del local, como un embudo o un atractor perfecto, de modo que, una vez en la zona de las mesas, el cliente se siente empujado a seguir adelante y pedir. Un diseño simple y directo, con una amplia zona despejada ante el mostrador, de tal forma que no hay opción para entretenerse en actividades intermedias, salvo elegir el menú y hacer el pedido. Aunque es usual tener que hacer cola ante el mostrador, la comida se pide, se recoge y se paga con mucha rapidez. La escasa variedad de los menús permite una elección bastante sencilla, lo que contrasta con el abanico de posibles elecciones de platos que presentan otros restaurantes. La carta se muestra al completo ante nuestros ojos en la cartelería 
extendida sobre el mostrador, a una distancia que no puede ser captada de un vistazo, de tal modo que la cercanía y la iluminación se imponen visualmente, creando la impresión de grandeza o de cantidad y variedad. La escasa variedad de opciones y la presión de las empleadas que salen a tomar directamente las órdenes del cliente cuando las colas son algo mayores, configuran una mecánica repetida y estandarizada donde apenas da tiempo a pensar. Hay que decidir rápidamente y seguir con el programa. Tampoco debemos olvidar la habitual pregunta de si se desea convertir el menú de tamaño mediano a uno más grande por unos pocos céntimos, pregunta que habitualmente se responde de manera afirmativa. La cantidad es barata; la elección, rápida.

El mobiliario. El mobiliario y la ambientación están pensados para que la comida se sirva en un máximo de quince minutos y pueda ser consumida en menos de veinte, creando la idea de que es el sitio adecuado para calmar el hambre en el menor tiempo posible. La regla parece ser que las sillas sean rígidas, apilables y carecer de tapizados, cojines y rellenos, sin obviar los parámetros ergonómicos mínimos. Hay excepciones, pero su comodidad es muy relativa, como en el caso de taburetes acolchados que carecen de respaldo, o los sillones con el respaldo completamente vertical. En definitiva, el mobiliario no invita a arrellanarse y prolongar la sobremesa. En la elección de las mesas se tiene en cuenta el tamaño, el tipo de producto que se va a consumir, la forma de consumirlo (con cubiertos o con la mano) y la manera en que está servido.

Los materiales utilizados en el mobiliario son duraderos, resistentes al uso, fáciles de limpiar y responden a cierta estética identificativa. Los colores de los establecimientos no son elegidos al azar. Por ejemplo, frente a los azules usados comúnmente en heladerías o tiendas de congelados, tonos que recuerdan a situaciones o lugares fríos, los más utilizados en establecimientos de comida rápida son los rojos, amarillos, naranjas y ocres, colores que sugieren alimentos calientes y a la vez informalidad. En el lenguaje de publicistas y diseñadores, el amarillo, por ejemplo, representa alegría, felicidad y energía; un color que reclama la atención, provoca sensaciones agradables, óptimo para niños y actividades de ocio, el cual se considera asociado con productos baratos (López y Montserrat, 2009) ${ }^{11}$.

La iluminación en este tipo de negocios debe asemejarse al máximo a la luz del día. Los expertos en arquitectura gastronómica creen que esto empuja a la persona a no acomodarse demasiado y sentir la necesidad de continuar el recorrido. Para conseguir este efecto, aconsejan combinar la luz blanca fluorescente con la calidez de la alógena en, por lo menos, el treinta por ciento del local ${ }^{12}$.

El diseño del mobiliario y de la ambientación mantiene un aire de sencillez, resultado de una elaboración concienzuda que combina un sentido pragmático del comportamiento de los clientes con un esfuerzo de originalidad y el mantenimiento de la imagen de marca. Ya sean redondeadas o rectas, las líneas son suaves, con una amplia variedad de posibilidades de diseño y de distribución. A pesar de que muchos locales son espaciosos, los tamaños de sillas y mesas están ajustados a las necesidades inmediatas de espacio de la persona, tal como vienen marcadas por el tamaño de bandejas y recipientes de comida. Cierta incomodidad calculada, pensada para no extender el tiempo de ocupación de un asiento, se combina así con un diseño de interiores atractivo, funcional y de cierto estilo futurista, original de la cadena.

\footnotetext{
${ }^{11}$ El simbolismo del color es un asunto complejo que se presta a burdas simplificaciones en manos de publicistas y de ciertos psicólogos que tratan las cuestiones ambientales de un modo determinista, con una idea de causalidad mecánica que desafía a su contenido social (simbólico, semántico). El simbolismo es un asunto que debe ser analizado en referencia a una larga y antiquísima tradición que se encuentra, por ejemplo, en los saberes gnósticos, en el simbolismo alquímico, en la historia del arte y en el pensamiento antiguo. Cualquier hipótesis sobre el color que ignore esta dimensión histórica y cultural no pasará de ser una reflexión descontextualizada de escaso valor.

${ }^{12}$ El arquitecto Roberto Buffadossi (2010) expone con más detalle estas ideas sobre iluminación y arquitectura gastronómica. (Insistimos, lea de nuevo la nota anterior).
} 
La cartelería y algunos elementos simbólicos, como la $M$, resultan desproporcionadamente grandes en relación con el mobiliario y el espacio personal asignado en las mesas. La lógica del exceso se impone visualmente.

La comida. El menú de McDonald's incluye un conjunto de alimentos que se comen sin cubiertos, directamente con los dedos (por ejemplo, McNuggets de pollo y patatas fritas, que se pueden comer de un bocado), con el resultado de que toda la comida se consume por lo general en muy pocos minutos. Todo ello envuelto en envases donde se muestra la imagen ideal, sin desperfectos, de lo que te vas a comer, cuando habitualmente lo que aparece una vez abierta la caja difiere mucho de las imágenes retocadas con editores digitales de imágenes.

Como hay muy pocos elementos que induzcan a perder tiempo, son los propios clientes quienes suelen recoger los restos del almuerzo y las bandejas de plástico, lo depositan todo en contenedores que se encuentran siempre cercanos y salen rápidamente del local dispuestos a seguir con sus actividades. La mesa está lista para el siguiente grupo de clientes sin apenas necesidad de preparación.

McDonald's remarca el aspecto de la cantidad en los nombres de sus productos, especialmente el Big Mac, como si la contemplación de una gran cantidad de comida estimulara el apetito para comer más de lo habitual. Cuando almorzamos en un restaurante de comida rápida, nos situamos en un contexto donde la voracidad es algo normal y no está mal vista. Está permitido comer con las manos, norma social impensable en restaurantes de otras características. Una gran hamburguesa se considera apetecible simplemente porque es grande, reforzando la impresión de estar adquiriendo un almuerzo verdaderamente económico. Curiosamente, esta insistencia en la cantidad es llamativamente superior a los mensajes o imágenes que se centran en la cuestión de la calidad.

Conseguir mucha comida a un precio moderado en los restaurantes de comida rápida es más una ilusión que una realidad. Los refrescos contienen mucho hielo, los panecillos son pequeños en algunos productos, dejando que la carne rebose alrededor, y son grandes y blandos en otras ocasiones, logrando que una hamburguesa pequeña parezca mayor. Las raciones de patatas fritas son particularmente engañosas. Se utilizan palas de cocina especiales para recoger las patatas, de tal manera que parece haber una cantidad mayor. La base de las cajitas de la ración grande está abombada hacia arriba para que las patatas sobresalgan. De hecho, y dado su precio, en cada paquete hay pocas patatas a cambio de lo que se paga. Más aún, en las patatas hay un elevadísimo margen de beneficio.

El cliente de McDonald's no busca una comida deliciosa y agradable. Lo que recibe es una comida saturada de calorías e hidratos de carbono, con la apariencia de una ración grande, suficiente para terminar rápidamente con el trámite del almuerzo, sentirse saciado y pasar a la siguiente actividad que quiera realizar.

Las bandejas en que se entrega y traslada la comida son pequeñas, muy ajustadas al tamaño del menú. En un efecto de figura y fondo, el reducido tamaño de las mesas y las bandejas hace que destaque y parezca mucho mayor la proporción del menú. Todas las bandejas incluyen un mantel de papel, con diseños muy diversos, coloridos y llamativos, que se aprovechan para trasladar múltiples mensajes. Incluyen juegos o imágenes de películas infantiles, reclamos identitarios fidelizadores, reclamos para consumir los menús supersized o campañas sobre el valor ecológico y nutritivo de sus productos.

Cada alimento y bebida tienen su propio envase diseñado específicamente. La imagen de marca está presente en todos ellos; no hay lugar donde poner la vista en el local que no incluya la $M$ u otros elementos identificatorios de la cadena. Los tamaños de los envases, bien por contraste (helados, por ejemplo) o bien por exceso (hamburguesas, refrescos) crean la impresión de una gran cantidad de 
producto. Las fotografías exteriores combinan, igual que los manteles, elementos y formas identitarias, motivos infantiles, fotos retocadas que presentan los menús del mejor modo posible y mensajes múltiples (información nutricional, apelaciones a la calidad de los productos o al compromiso de McDonald's con la salud o el medio ambiente). Todos los envases son desechables, reduciendo el tiempo y el esfuerzo necesario para procesar los restos de la comida.

\section{Conclusiones}

De nuestros comentarios e interpretaciones anteriores, concluimos que el paisaje visual y simbólico de McDonald's está escrito atendiendo a tres tipos de valores: eficiencia - todo sucede de manera rápida, sin errores ni sorpresas relevantes, sin dudas-, identidad - los elementos identitarios ubicuos sugieren un esfuerzo permanente e intenso de fidelización - y cantidad —en un ambiente normalizado bajo la lógica semántica del exceso-. Desde la imagen exterior hasta el diseño de los manteles, desde la ambientación hasta las pautas de atención al cliente, cada elemento presente en el local combina estos valores en distinta medida, de tal modo que sirve para concretar el simbolismo de la cadena, para trasladar la imagen de marca, para dar coherencia al conjunto y significado a cada elemento particular. Siguiendo el planteamiento de Roland Barthes (1988), podríamos considerar a la variedad de elementos comunes presentes en los locales (el mobiliario, los carteles, los colores, las hamburguesas y refrescos, entre otros) como los sintagmas básicos utilizados para crear el diseño de cada restaurante, y que remiten o vehiculan, más allá de su sentido funcional primario, a un segundo nivel de interpretación en el que se traslada la imagen de la cadena. La combinación de estos elementos y valores permite una gran flexibilidad dentro de un planteamiento coherente, de cara al diseño de tan vasta red de locales en todo el mundo, manteniendo una fuerte imagen de marca y una gran capacidad de adaptación a contextos socioculturales variados.

La idea de eficiencia sintetiza los valores de rapidez, sencillez, confianza y seguridad que identifica Ritzer (1996). La eficiencia parece el valor clave de la lógica empresarial de la cadena y de la organización ambiental de cada restaurante, con los demás valores y elementos alineándose para crear la impresión de que se recibe mucho por poco, cantidad a cambio de un esfuerzo reducido, a cambio de poco dinero y poco tiempo. Recursos, procesos y esfuerzos están optimizados en su mecánica; los resultados son previsibles, rápidos y seguros. Ninguna otra cadena de restaurantes es capaz de semejante eficiencia; aunque esta afirmación resultará paradójica para quien no valore la comida rápida, McDonald's (y alguno de sus competidores) puede ser considerado el mejor negocio de restauración del mundo. Para el cliente, McDonald's es un negocio sencillo, que utiliza un lenguaje fácil de comprender, con pocos elementos pero de gran impacto visual y de gran coherencia simbólica: no necesita pensar mucho, el menú es limitado, la elección rápida, el programa de comportamientos repetitivo; no tiene que esperar mucho y tampoco tardará más que lo justo en terminar su comida y salir del local.

El lenguaje del exceso (la cantidad) forma parte sustancial del simbolismo del restaurante. Reclamos, recipientes y comidas se presentan en un tamaño exagerado (el Big Mac, el vaso gigante de refresco, el logotipo de la $M$, la figura del payaso, la zona de juegos, la cartelería, etc.). Lo que inicialmente no parecería más que una estrategia de venta o un modo subrepticio de hacer creer al cliente que se le ofrecen grandes cantidades de comida, se ha convertido en parte esencial del paisaje simbólico del restaurante y de los estilos de alimentación urbana. La cantidad es una mentira bien trabada, pero con un gran poder, al fin y al cabo, para imponerse como el discurso válido que identifica, resume y narra la experiencia "macdonald". 
El exceso fuera de lugar, la imagen como sustituta válida de la realidad; la rapidez como sinónimo de lo efímero, del valor de lo momentáneo; la sustitución del acontecimiento social del almuerzo y la sobremesa por un rápido trámite, un paréntesis entre el paso por las tiendas del centro comercial; prácticas e imágenes sociales que encajan bien en los discursos teóricos sobre la posmodernidad, el simulacro o la sociabilidad transitoria y líquida de Jean Baudrillard (1998), Gilles Lipovetsky (2006) o Zygmunt Bauman (2003). Es como si Hollywood hubiera inventado un restaurante de mentira (una antirestaurante, según los cánones tradicionales europeos y mediterráneos) para la escenografía de cartón piedra de sus películas, y la mentira hubiera triunfado como el modelo de alimentación de mayor éxito y proyección por todo el mundo. El modelo McDonald's es una metáfora perfecta de la primera posmodernidad, aquella que se recreaba en la elevación a iconos culturales de objetos de consumo aparentemente vanos y desechables (Jameson, 1991; Lyon, 2000). Más allá de ser un elemento del paisaje cultural de nuestro tiempo, es una institución social que ha creado y condicionado nuestro presente y nuestro futuro inmediato. No es un mero indicador de superficialidad y liquidez, sino el modelo de alimentación que ha construido nuestra sociabilidad superficial y efímera.

No nos interesa aquí si los menús son hipercalóricos o si comer rápido promueve más o menos la obesidad. Sabemos por Super Size Me que es un veneno, pero tampoco más, no nos engañemos, que el abuso de muchos alimentos (bollería, embutidos, tocinos...), locales (bares, pubes) y sustancias (alcohol, tabaco, cocaína...), muchos de las cuales no están señalados de forma tan negativa. Los efectos obesogénicos deberían ser fácilmente contrarrestados con otras comidas y con ejercicio, según dicen. La "criminalización" de McDonald'ses coherente con el discurso fácil que las autoridades sanitarias, ciertos sectores empresariales de la moda y los medios de comunicación han creado en torno a la imagen terrible y sobregeneralizada de la obesidad como enfermedad (Braziel y LeBesco, 2001). La pandemia es más convincente si se vincula con la idea de comida basura o chatarra, considerando a todo el planeta globalizado como reflejo directo de algunas costumbres y polémicas públicas de la sociedad yanqui.

Nos interesa más llamar la atención sobre la normalización de un modelo de alimentación y de relaciones sociales que se ha establecido entre nosotros y que se está constituyendo en parte central de nuestros hábitos sociales. McDonald's participa del mismo universo social de significados que el estigma antiobesidad, forma parte de la dialógica que otorga centralidad y virtualidad a la discusión sobre salud, estética y obesidad. Sin embargo, las discusiones sobre la comida rápida no remiten a un análisis del modelo social o del éxito económico, sino a la feroz crítica contra la obesidad; hablar sobre McDonald's es poner subrepticiamente sobre el tapete el papel que juega en la extensión de la pandemia, inseparablemente unidos como imagen de todo lo malo, lo impropio o la fealdad que nuestra sociedad pone sobre la gordura y todo lo que tenga que ver con ella. Hablar mal sobre McDonald's es, en una parte importante, hacer pública la crítica y normalizar el rechazo de las personas obesas, un elemento más de la implacable campaña contra todos aquellos que no respetan los estándares de la delgadez políticamente correcta (Gard, 2009).

\section{Referencias}

Aragonés, Juan Ignacio y María Amérigo (1998). Psicología Ambiental. Aspectos conceptuales y metodológicos. En Juan Ignacio Aragonés y María Amérigo (Comps.), Psicología Ambiental (pp.21-41). Madrid: Pirámide. 
Baudrillard, Jean (1998). Simulacra and simulations. En Mark Poster (Ed.), Jean Baudrillard, Selected Writings (pp. 166-184). Palo Alto, CA: Stanford University Press. Extraído el 31 de octubre, de http://www.stanford.edu/dept/HPS/Baudrillard/Baudrillard_Simulacra.html

Bauman, Zygmunt (2003). Modernidad líquida. México, D.F.: Fondo de Cultura Económica.

Barthes, Roland (1988). Mitologías. Madrid: Siglo XXI.

Braziel, Jana E. y Kathleen LeBesco (Eds.) (2001). Bodies out of bounds: Fatness and transgression. Berkeley, CA: University of California Press.

Buffadossi, Roberto (2010). Tipos de iluminación en arquitectura gastronómica. Extraído el 31 de octubre, de http://www.espaciogastronomico.com.ar/news/182.html

Dear, Michael (2000). The postmodern urban condition. Oxford, UK: Blackwell.

Eckermann, Liz (2009). Theorising self-starvation: Beyond risk, governmentality and the normalizing gaze. En Helen Malson y Maree Burns (Eds.), Critical feminist approaches to eating dis/orders (pp. 9-21). Londres: Routledge.

Fernández-Ramírez, Baltasar; Elia Esquirol y Cristina Rubio (2009). Posición de la mujer en las noticias sobre obesidad en la prensa escrita. En M ${ }^{a}$ Elena Jaime de Pablos (Ed.), Identidades femeninas en un mundo plural (pp. 684-703). Almería: Arcibel. Extraído el 31 de octubre, de http://www.audem.com/publicaciones.php

Foucault, Michel (1977). Historia de la medicalización. Educación Médica y Salud, 11(1), 3-25.

Gard, Michael (2009). Understanding obesity by understanding desire. En Helen Malson y Maree Burns (Eds.), Critical feminist approaches to eating dis/orders (pp. 35-45). Londres: Routledge.

Gómez, Rafael (2001). Análisis de la imagen. Estética audiovisual. Madrid: Ediciones del Laberinto.

Hartley, Cecilia (2001). Letting ourselves go. En Jana E. Braziel y Kathleen LeBesco (Eds.), Bodies out of bounds: Fatness and transgression (pp. 60-73). Berkeley, CA: University of California Press.

Jameson, Frederic (1991). El posmodernismo o la lógica cultural del capitalismo avanzado. Barcelona: Paidós.

Kirk, Sara F.L.; Penney, Tarra L. y McHugh, Tara-Leigh (2010). Characterizing the obesogenic environment: the state of the evidence with directions for future research. Obesity Reviews, 11(2), 109-117.

Lakoff, George y Mark Johnson (1998). Metáforas de la vida cotidiana. Madrid: Cátedra.

Lipovetsky, Gilles (2006). Los tiempos hipermodernos. Barcelona: Anagrama.

López, Jesús Ángel y Juan M. Monserrat (2009). Estrategias de comunicación corporativa en las franquicias de restauración. Análisis cromático de la identidad visual. Revista Latina de Comunicación Social, 12(64), 300-314.

Lyon, David (2000). Postmodernidad. Madrid: Alianza.

Macdonald, Cameron L. y Carmen J., Sirianni (1996). Working in the service society. Philadelphia, PA: Temple University Press.

Malson, Helen y Burns, Maree (Eds.) (2009). Critical feminist approaches to eating dis/orders. Londres: Routledge.

Ritzer, George (1996). La McDonalización de la sociedad. Un análisis de la racionalización de la vida cotidiana. Barcelona: Ariel.

Rose, Nikolas y Peter Miller (1992). Political power beyond the State: Problematics of government. The Bristish Journal of Sociology, 43(2), 173-205.

Sobal, Jeffery y Brian Wanskink (2007). Kitchenscapes, tablescapes, platescapes, and foodscapes: Influences of microscale built environments on food intake. Environment \& Behavior, 39(1), 124142. 
Sommer, John W. (1975). Fat city and hedonopolis: The American urban future? En Ronald Abler, D. Janelle, A. Philbrick, y J. Sommer (Eds.), Human geography in a shrinking world (pp. 132-146). North Scituate, MA: Duxbury.

Spurlock, Morgan (Productor y director) (2004). Super Size Me [Película]. Estados Unidos: Kathbur Pictures y The Con, en asociación con Studio on Hudson.

Sui, Daniel Z. (2003). Musings on the fat city: Are obesity and urban forms linked? Urban Geography, 24(1), 75-84.

Swinburn, Boyd; Egger, Garry y Raza, Fezeela (1999). Dissecting obesogenic environments: The development and application of a framework for identifying and prioritizing environmental interventions for obesity. Preventive Medicine, 29(6), 563-570.

Vivas, Pep; Isabel Pellicer-Cardona y Óscar López-Catalán (2008). Ciudad, tecnología y movilidad: espacios de sociabilidad transitoria. En Baltasar Fernández-Ramírez y Tomeu Vidal (Eds.), Psicología de la ciudad. Debate sobre el espacio urbano (pp. 121-136). Barcelona: UOC.

Vivas, Pep; Óscar López-Catalán; Baltasar Fernández-Ramírez e Isabel Pellicer-Cardona (en prensa). Place-identity and appropriation of transit spaces: Traditional vs standardized food and beverage facilities in Barcelona subway. Mobilities.

Wells, Nancy M.; Ashdown, Susan P.; Davies, Elizabeth H.S.; Cowett, F.D. y Yang, Yizhao (2007). Environment, design, and obesity: Opportunities for interdisciplinary collaborative research. Environment \& Behavior, 39(1), 6-33.

Este texto está protegido por una licencia Creative Commons.
Usted es libre de copiar, distribuir y comunicar públicamente la obra bajo las siguientes condiciones:
Reconocimiento: Debe reconocer y citar al autor original.
No comercial. No puede utilizar esta obra para fines comerciales.
Sin obras derivadas. No se puede alterar, transformar, o generar una obra derivada a partir de esta obra.
Resumen de licencia - Texto completo de la licencia

